prolapse. The second was also an elderly woman with myxoedema who initially responded to cefoxitin but relapsed with the same infecting organism in the urine four weeks later. Both had residual urine in the bladder. All of the patients suffering from pyelonephritis were cured by cefoxitin but two of the eight patients with septicaemia failed to respond. All four patients with intra-abdominal sepsis were cured by cefoxitin treatment, combined in three with surgical drainage.

Cefoxitin appears to share with the cephalosporins and penicillins the property of rarely producing serious adverse reactions. Apart from transient derangement of liver function, and phlebitis in one patient, none of the patients developed untoward reactions to the antibiotic. Furthermore, it has been suggested ${ }^{13}$ that cross-allergenicity between the cephalosporins and the cephamycins might not occur because of the differing chemical structures. There was no evidence of nephrotoxicity as demonstrated by increased serum urea or creatinine concentrations, both of which were measured before, during, and after treatment with cefoxitin.

The present uncontrolled study suggests that cefoxitin will have a place in the management of serious infections, particularly in the peritoneal cavity and biliary and renal tracts. Serum, urine, and bile concentrations of the antibiotic greatly exceed the MIC required for clinically important Gram-negative organisms.

\section{References}

${ }^{1}$ Albers-Schonberg, G, Arison, B H, and Smith, J L, Tetrahedron Letter, 1972, 29, 2911.

${ }^{2}$ Karady, S, et al, fournal of the American Chemical Society, 1972, 95, 1410.

${ }^{3}$ Kosmidis, J, et al, British Medical fournal, 1973, 4, 653.

${ }^{4}$ Miller, A K, et al, Antimicrobial Agents and Chemotherapy, 1974, 5, 33.

${ }^{5}$ Hamilton-Miller, J M T, Kerry, D W, and Brumfitt, W, Fournal of Antibiotics, 1974, 27, 42.

- Neu, H C, Antimicrobial Agents and Chemotherapy, 1974, 6, 170.

${ }^{7}$ Moellering, R C, Dray, M, and Kunz, L J, Antimicrobial Agents and Chemotherapy, 1974, 6, 320.

${ }^{8}$ Brumfitt, W, et al, Antimicrobial Agents and Chemotherapy, 1974, 6, 290.

9 Stewart, D, and Bodey, G P, fournal of Antibiotics, 1976, 29, 181.

10 O'Callaghan, C, et al, Antimicrobial Agents and Chemotherapy, 1976, 9, 511.

${ }^{11}$ Norrby, R, Brorsson, J-E, and Seeberg, S, Antimicrobial Agents and Chemotherapy, 1976, 9, 506.

${ }_{12}$ Sonneville, P F, et al, European fournal of Clinical Pharmacology, 1976, 9, 397.

${ }^{13}$ Hamilton-Miller, J M T, and Brumfitt, W, Infection, 1975, 4, 183.

(Accepted 17 February 1977)

\title{
Self-poisoning with barbiturates in England and Wales during 1959-74
}

\author{
M W JOHNS
}

British Medical fournal, 1977, 1, 1128-1130

\section{Summary}

Hospital admissions due to acute barbiturate poisoning per million population in England and Wales have decreased since 1965 at about the same rate as NHS prescriptions for barbiturates. Admissions due to poisoning with other drugs have increased, but, largely because the benzodiazepine hypnotics and tranquillisers are much less toxic than the barbiturates that they are replacing, deaths from poisoning with all solids and liquids have decreased. The risk of death from selfpoisoning associated with each barbiturate prescription has increased two and a half times since 1961, perhaps partly because greater quantities of barbiturate are being dispensed with each prescription and partly because patients for whom these drugs are still being prescribed would, in the event of an overdose, be unlikely to be found and admitted to hospital in time owing to their age and social circumstances. There is now little to justify prescribing barbiturate hypnotics or sedatives for anyone.

\section{Introduction}

During 1959-74 over 27000 people died in England and Wales from acute poisoning with self-administered barbiturates. During that period some 225 million prescriptions for bar-

MRC Environmental Physiology Unit, London School of Hygiene and Tropical Medicine, London WC1E 7HT

$M$ W JOHNS, MB, PHD, member of scientific staff biturate hypnotics and sedatives were dispensed within the NHS, apart from those dispensed from hospital pharmacies, for which detailed figures are not available.

My aim was to investigate changes in the overall incidences of death and hospital admission due to self-poisoning with barbiturates in relation to their availability on NHS prescriptions since 1959.

\section{Methods}

The yearly number of deaths in England and Wales from poisoning with all solids and liquids, including medicinal agents and household poisons, and those due to barbiturates were derived from the annual lists of poisonings issued by the Registrar General. Cases in which barbiturates were ingested along with other poisons were listed separately from those caused by barbiturates alone. In 1974 alcohol was specifically mentioned as a contributory cause of death in $15 \%$ of barbiturate deaths, but because the contribution of alcohol to deaths in earlier years was uncertain it has been omitted from consideration. Other errors and omissions would undoubtedly arise in the reporting of causes of death and, later, in their classification, but I have assumed that such errors did not appreciably affect the major trends in the years covered by this investigation.

Estimates of the total number of hospital deaths and discharges after poisoning with all medicinal agents (ICD codes N960-N979) and barbiturates alone (coded N971 until 1967, then N967.0) were derived from the Hospital In-Patient Enquiries made by the Department of Health and Social Security. The yearly number of prescriptions for barbiturate hypnotics and sedatives (omitting general anaesthetics and anticonvulsants) and average number of doses per prescription were estimated from a $0.5 \%$ sample of all NHS prescriptions handled by the Department of Health and Social Security, with the exclusion of those dispensed from hospital pharmacies. These figures underestimate the overall availability of barbiturates in the community but I have assumed that they reflect changes in the latter from year to year with reasonable accuracy.

Yearly death rates and rates of hospital admission were calculated, firstly, per million population in England and Wales, and, secondly, per million NHS prescriptions for barbiturate hypnotics and sedatives. 


\section{Results}

\section{DEATHS}

During 1959-74 barbiturates were the commonest agents among all the solids and liquids causing death by poisoning: $67 \%$ of all such deaths involved barbiturates alone, and another $5 \%$ involved barbiturates with other substances, most of which were also medicinal agents. About two-thirds of barbiturate deaths were among women, the highest incidence in both sexes occurring in people 45-64 years of age. Two-thirds of all cases were reported as suicides, and the remainder as accidents or of undetermined intention.

During 1959-64 deaths from poisoning with all solids and liquids and those due to barbiturates more than doubled in relation to each million population (table I). Thereafter, deaths from poisoning with all solids and liquids increased slightly until 1969 and then remained relatively constant, about 3000 deaths occurring yearly. By contrast, deaths due to barbiturates reached a plateau between 1964 and 1969 and then decreased by an average of $6.2 \%$ a year. These figures do not include cases in which barbiturates were involved in combination with other poisons because the contribution of each to the subject's death could not be ascertained. Between $86 \%$ and $92 \%$ of all barbiturate deaths each year were caused by barbiturates alone, however, and the trend in the death rate from year to year was virtually the same whether or not these additional cases were included.

Although barbiturates were cited in a decreasing proportion of poisoning cases after 1968, they were still directly implicated in 1643 deaths in 1974-that is, in $53.5^{\circ}$ o of all fatal poisonings. Six types of barbiturate caused at least $70^{\circ}{ }_{0}$ of these deaths, four types causing $60^{\circ}$. Amylobarbitone sodium with quinalbarbitone sodium caused most deaths-that is, 518 in 1974 . Other barbiturates concerned, in decreasing order of frequency, were pentobarbitone sodium, amylobarbitone sodium, butobarbitone, amylobarbitone, and quinalbarbitone sodium. These five drugs caused 619 deaths and contributed to many others in 1974. For comparison, all the non-barbiturate hypnotics together (for which there were 9.5 million prescriptions in 1974 , compared with 8.6 million for all barbiturate hypnotics and sedatives) caused 120 deaths, and all the antidepressants-tricyclic as well as monoamine oxidase inhibitors (a total of 21.5 million prescriptions in 1974)-187, although like the barbiturates they also contributed to other deaths.

\section{HOSPITAL ADMISSIONS}

The yearly number of hospital admissions due to poisoning with all medicinal agents per million population was almost five times higher in 1972 (the last year for which data were available) than it had been in 1959 (table I). The average hospital mortality for all such poisonings was $2.3 \%$ in 1959 , falling to $1.2 \%$ by 1967 . By contrast, hospital admissions due to poisoning with barbiturates doubled between 1959 and 1963 and thereafter decreased progressively by an average of $6.3 \%$ a year.

Even if the average mortality for all cases of barbiturate poisoning admitted to hospitals had been as high as $8 \%$ (which is unlikely, since it is less than $1 \%$ in some centres ${ }^{1}$ ) the difference between the estimated number of deaths in hospital and the total number of deaths registered each year suggests that most of the barbiturate deaths occurred without the patients being admitted to hospital and, presumably, therefore, without receiving medical care after taking an overdose.

\section{PRESCRIPTIONS FOR BARBITURATES}

Prescriptions for barbiturates reached a maximum in $1965(36 \cdot 2 / 100$ population, or a total of 17.2 million that year) and then decreased by an average of $7.5 \%$ a year. Sedative-strength barbiturates, however, were replaced by non-barbiturate alternatives more rapidly than was the case with the hypnotics. As a result prescriptions for the single most popular brand of the hypnotics-amylobarbitone sodium with quinalbarbitone sodium (Tuinal) 100 and $200 \mathrm{mg}$ - and for pentobarbitone sodium $100 \mathrm{mg}$ together constituted $22.4 \%$ of all barbiturate prescriptions in 1974 compared with $15.6 \%$ in 1965 .

Between 1965 and 1974 the average number of dose units per prescription increased progressively for many drugs. For example, prescriptions for amylobarbitone sodium with quinalbarbitone sodium $200 \mathrm{mg}$ provided an average of 41 capsules each in 1965, increasing to 48 in 1974 ( $9.6 \mathrm{~g}$ barbiturate per prescription). Similarly, prescriptions for the sedative amylobarbitone $50 \mathrm{mg}$ provided an average of 67 tablets in 1965 compared with 85 tablets in 1974 ( $4.25 \mathrm{~g}$ barbiturate).

Deaths from poisoning with barbiturates per million prescriptions increased almost two and a half times between 1961 and 1974 (table II). Inclusion of the few cases in which barbiturates were concerned in combination with other drugs did not alter this trend. Thus, although the prescribing of barbiturates was halved between 1965 and 1974, the overall risk of death from self-poisoning associated with each prescription continued to increase. By contrast, the number of hospital admissions due to barbiturate poisoning per million prescriptions varied more irregularly and was as high in 1963 as it was in 1971 (table II).

\section{Discussion}

These results emphasise the magnitude of the continuing problem of acute barbiturate poisoning when viewed nationally. The progressive displacement of barbiturates by less toxic hypnotics and tranquillisers (particularly the benzodiazepines)

TABLE I-Deaths and hospital admissions due to self-poisoning with solids and liquids and with barbiturates per million population living in England and Wales, and number of NHS prescriptions for barbiturate hypnotics and sedatives (excluding those dispensed in hospital pharmacies) per 100 population

\begin{tabular}{|c|c|c|c|c|c|}
\hline \multirow{2}{*}{ Year } & \multicolumn{2}{|c|}{ Deaths/million population due to: } & \multicolumn{2}{|c|}{ Hospital admissions/million population due to: } & \multirow{2}{*}{$\begin{array}{l}\text { NHS prescriptions for } \\
\text { barbiturates/100 population }\end{array}$} \\
\hline & All solids and liquids & Barbiturates & All medical agents & Barbiturates & \\
\hline $\begin{array}{l}1959 \\
1960 \\
1961 \\
1962 \\
1963 \\
1964 \\
1965 \\
1966 \\
1967 \\
1968 \\
1969 \\
1970 \\
1971 \\
1972 \\
1973 \\
1974\end{array}$ & $\begin{array}{l}28 \cdot 1 \\
30 \cdot 4 \\
34 \cdot 5 \\
43 \cdot 2 \\
53 \cdot 4 \\
56 \cdot 3 \\
55.5 \\
56 \cdot 1 \\
56 \cdot 4 \\
58 \cdot 4 \\
62.3 \\
59 \cdot 8 \\
62 \cdot 7 \\
59 \cdot 6 \\
59 \cdot 3 \\
62 \cdot 4\end{array}$ & $\begin{array}{l}17 \cdot 0 \\
20 \cdot 0 \\
22 \cdot 7 \\
28 \cdot 6 \\
36 \cdot 4 \\
38 \cdot 0 \\
39 \cdot 1 \\
39 \cdot 3 \\
39 \cdot 1 \\
37 \cdot 5 \\
40 \cdot 1 \\
36 \cdot 6 \\
36 \cdot 8 \\
34 \cdot 8 \\
31 \cdot 5 \\
29 \cdot 2\end{array}$ & $\begin{array}{r}380 \\
440 \\
520 \\
620 \\
830 \\
910 \\
960 \\
1050 \\
1190 \\
1290 \\
1560 \\
1630 \\
1750 \\
1870\end{array}$ & $\begin{array}{l}166 \\
190 \\
228 \\
260 \\
350 \\
345 \\
328 \\
328 \\
290 \\
244 \\
270 \\
238 \\
230 \\
200\end{array}$ & $\begin{array}{l}32 \cdot 7 \\
33 \cdot 9 \\
33 \cdot 9 \\
34 \cdot 1 \\
36 \cdot 2 \\
35 \cdot 1 \\
33 \cdot 5 \\
31 \cdot 6 \\
29 \cdot 3 \\
26 \cdot 9 \\
24 \cdot 0 \\
21 \cdot 4 \\
19 \cdot 5 \\
17 \cdot 5\end{array}$ \\
\hline
\end{tabular}

TABLE II-Deaths and hospital admissions due to poisoning with barbiturates per million prescriptions within NHS, excluding hospital pharmacies

\begin{tabular}{|c|c|c|c|c|c|c|c|c|c|c|c|c|c|c|c|}
\hline & Year: & 1961 & 62 & 63 & 64 & 65 & 66 & 67 & 68 & 69 & 70 & 71 & 72 & 73 & 74 \\
\hline $\begin{array}{l}\text { Deaths } \\
\text { Hospital admissions }\end{array}$ & $\because$ & $\begin{array}{r}69 \\
700\end{array}$ & $\begin{array}{r}85 \\
720\end{array}$ & $\begin{array}{r}107 \\
1030\end{array}$ & $\begin{array}{r}111 \\
1010\end{array}$ & $\begin{array}{l}108 \\
910\end{array}$ & $\begin{array}{l}112 \\
930\end{array}$ & $\begin{array}{l}117 \\
890\end{array}$ & $\begin{array}{l}119 \\
720\end{array}$ & $\begin{array}{l}137 \\
920\end{array}$ & $\begin{array}{l}136 \\
890\end{array}$ & $\begin{array}{r}153 \\
1050\end{array}$ & $\begin{array}{l}162 \\
940\end{array}$ & 176 & 165 \\
\hline
\end{tabular}


since $1965^{\circ}$ has undoubtedly stemmed an increase in deaths from drug overdosage, and there has not been a compensatory increase in suicides by other means. ${ }^{3}$ The number of barbiturate deaths per million population, however, did not decrease as rapidly after 1965 as might have been expected from the decreases in the corresponding rates for hospital admission and for barbiturate prescribing. One factor that probably militated against such a decrease was the concomitant increase in the quantity of barbiturate dispensed with each prescription, partly because more dose units were given each time and partly because the proportion of hypnotic-strength doses increased in relation to sedative doses. In addition, patients who continued to take barbiturates may have had a greater-than-average risk of dying from an overdose because of their age or because their social circumstances made it unlikely that they would be found and admitted to hospital before they died. ${ }^{4}$ These conclusions are supported by the increasing death rate from barbiturate poisoning per million prescriptions and by the observations that most deaths involved barbiturates of hypnotic rather than sedative strength and occurred without the patients being admitted to hospital.

Compared with barbiturate hypnotics the benzodiazepines nitrazepam and flurazepam are at least as effective in the short term (a few days) and are more effective in the long term, ${ }^{56}$ less apt to produce dependence, and much less toxic in overdosage. ${ }^{78}$ They are, however, more expensive. Most patients in general practice can be transferred from barbiturate to benzo- diazepine hypnotics provided that it is done gradually (over two to four weeks), and many can cope without hypnotics altogether if they are withdrawn gradually. ${ }^{9}$

Improvements in the hospital care of patients will not reduce the death rate from self-poisoning with drugs as much as would further limitation on the prescribing of barbiturates-that is, on the number of prescriptions and number of dose units, particularly those of hypnotic strength.

I thank the staff of the Department of Health and Social Security, particularly of the Statistics and Research Division, who provided much of the data.

\section{References}

${ }^{1}$ Matthew, H, Lancet, 1974, 1, 224.

2 Trethowan, W H, British Medical Yournal, 1975, 3, 749.

${ }^{3}$ Kreitman, N, British Fournal of Preventive and Social Medicine, 1976, 30, 86.

4 Barraclough, B M, and Pallio, D J, Psychological Medicine, 1975, 5, 55.

5 Kales, A, et al, Clinical Pharmacology and Therapeutics, 1975, 18, 356.

${ }^{6}$ Adam, K, et al, British Medical fournal, 1976, 1, 1558.

${ }^{7}$ Berger, F M, Clinical Pharmacology and Therapeutics, 1967, 8, 219.

${ }^{8}$ Barraclough, B M, Lancet, 1974, 1, 57.

9 Wells, F O, Fournal of the Royal College of General Practitioners, 1973, 23, 164 .

(Accepted 2 March 1977)
Department of Medicine, Royal Postgraduate Medical School, London W12 OHS

P E JONES, MSC, MRCP, research fellow and honorary senior registrar T J PETERS, PHD, FRCP, senior lecturer and honorary consultant physician is withdrawn from the diet. In about $15^{\circ}{ }_{0}$ of cases, however, the jejunal mucosa remains flat despite gluten withdrawl. These patients often require additional treatment with corticosteroids, parenteral nutrition, or elemental diets, but even then their condition may progressively deteriorate. ${ }^{1}$ This failure to regenerate villi might be due to impaired enterocyte production. We therefore used an organ culture technique to determine the enterocyte production rate in patients with coeliac disease.

\section{Patients and methods}

Jejunal mucosa was studied in four groups of patients: (a) 13 controls with histologically normal mucosa who had previously been suspected of having malabsorption; $(b)$ six patients with untreated coeliac disease who had flat mucosa (subtotal villous atrophy) and malabsorption of at least two dietary components including folate; $(c)$ seven patients whose jejunal mucosa remained flat despite prolonged documented gluten withdrawal; and $(d)$ nine patients with coeliac disease in whom gluten withdrawal had improved jejunal morphology; when studied these patients had either normal villi or only partial villous atrophy.

Jejunal biopsy specimens were collected with the Watson-Crosby capsule as part of the clinical management of the patients. The specimens were divided into representative pieces for routine histological examination, enzyme analysis, ${ }^{2}$ or organ culture. ${ }^{3}$ The investigations reported here were approved by the local ethical committee.

DNA synthesis was measured by culturing the mucosa for three hours with $135 \mu \mathrm{g}{ }^{3} \mathrm{H}$-thymidine (specific activity $74 \mathrm{Ci} / \mathrm{g}$; Radiochemical Centre, Amersham). The tissue was homogenised and DNA selectivity precipitated with cadmium chloride. ${ }^{4}$ The radioactivity was counted in triton-toluene scintillant with a Beckman LS 250 scintillation counter. For each patient DNA synthesis was measured 